\title{
Illegal or Undocumented: An Analysis of Immigrant Terminology in Contemporary American Media
}

\author{
Robin Lee Nelson ${ }^{1} \&$ Patricia Davis-Wiley ${ }^{2}$ \\ ${ }^{1}$ Central High School, Knox County Schools, Knoxville, Tennessee, United States \\ ${ }^{2}$ Theory and Practice in Teacher Education, The University of Tennessee, Knoxville, Tennessee, United States
}

Received: April 29, 2018

Accepted: May 15, $2018 \quad$ Available online: May 18, 2018

doi:10.11114/ijsss.v6i6.3254

URL: https://doi.org/10.11114/ijsss.v6i6.3254

\begin{abstract}
This purpose of this study was to analyze the terms illegal alien, illegal immigrant, and undocumented immigrant in order to determine if these legal synonyms exhibit pragmatic differences in actual practice found in American media. Studies have reported that differences in terminology, metaphor, and discourse framing largely serve to dehumanize or empower immigrants for partisan purposes in legal language (Johnson 1996), politics (Mehan 1997), and in the media (Santa Ana, 1999). Given the semantic presumption of criminality with the terms illegal alien and illegal immigrant, it can be argued that undocumented immigrant is used in more positive contexts in the media when compared with the terms illegal alien or illegal immigrant. In order to test this theory, the authors used the Corpus of Contemporary American English (COCA, 2016) to analyze the frequency, presumption of criminality in context, and different media outlets' use of illegal alien, illegal immigrant, and undocumented immigrant. Results of this study found that the terms illegal immigrant and illegal alien have been used significantly more in American media than the term undocumented immigrant, although that trend appears to be shifting. While there was little difference in the presumption of criminality with illegal immigrant and undocumented immigrant, contexts using illegal alien assumed criminality twice as often as the other terms. Fox News and CNN used terms with illegal much more than any other group, although CNN has largely phased the terms out of use in recent years; NPR used the term undocumented immigrant significantly more than other media.
\end{abstract}

Keywords: national identities, framing labels, immigration attitudes, undocumented immigrants

\section{Introduction}

Is the United States truly a nation of immigrants? While many Americans agree with this label and are quick tell the story of how their successful grandfather came to this country with two dollars in his pocket, do Americans truly believe that all people deserve a chance at the American dream? Based on the 2016 election battle cry of "Build a wall!" and the wide-spread approval of many Americans to "ban all non-U.S. born" from entering and residing in the U.S., it would be challenging for anyone to argue that all Americans, even today, are pleased about being a nation of immigrants, despite the accuracy of the phrase. Though many American citizens vocalize their distaste of immigrants, other religions, and races in less politically correct ways, the majority of Americans tend to express their disapproval through culturally acceptable discourse structures and terminology, which they feel exonerates them from accusations of racism.

\subsection{Illegal Alien/immigrant vs. Undocumented Immigrant}

Terminology is one of the ways in which people allow themselves to dehumanize others. One set of dehumanizing legal synonyms is illegal alien, illegal immigrant, and undocumented immigrant. Using the adjective illegal to describe a person instead of an action automatically may label him/her a criminal. The term alien is currently used by U.S. Citizenship and Immigration Services (2018) to describe foreigners who enter the United States without entry or immigrant visas. Undocumented immigrant simply refers to a foreigner without proper legal documents; yet, the label illegal alien may be ascribed to this same person. However, do the semantic implications of these terms match pragmatically, particularly in the media?

\subsection{Purpose of the Study}

The purpose of this study was to analyze American media's frequency of use of the terms illegal alien, illegal immigrant, and undocumented immigrant over time and the contexts in which they are used. Whereby, some might 
argue that these terms can be used interchangeably to denote the same meaning, do they not also convey a pejorative connotation in so doing?

\subsection{Research Questions}

In order to analyze the prevalence and pragmatic usage of the former terms, four research questions guided this study:

1. Which terms do American media tend to use most frequently: illegal alien, illegal immigrant, or undocumented immigrant?

2. How has immigration terminology in the media changed over time?

3. Do illegal immigrant and illegal alien presume criminality in context more than undocumented immigrant?

4. Which term is preferred in the media? Illegal alien, illegal immigrant, or undocumented immigrant?

\section{Review of Relevant Literature}

Current research shows that immigrants are frequently dehumanized and labeled or framed (Gamson \& Wolfsfled, 1993) as criminal through discourse framing structures, metaphors, and words like illegal alien or illegal immigrant in the media and court system. However, does the terminology reflect the discourse or is the discourse shaped by the terminology? Why are others so invested in using one term over another for the same individuals? Does using one term instead of another truly affect its perception?

American history has wrestled with creating terms for others that label them as lesser, but still allow its users to be seen as lacking racial biases. Gabbacia (2010) describes how Americans created the word immigrant in order to distinguish the undesirable foreigners (like the Chinese during that particular era) from the acceptable ones (White Americans moving westward), who identified with the term emigrant. Likewise, Paspalanova (2008) argues that the inaccuracy of the term illegal to describe a person, as only an act can be illegal, as is its use by politicians and the media to explicitly manipulate public opinion. Both Mehan (1997) and Pearson (2010) discuss the inherent threat that the term illegal immigrant elicits when compared with terms identifying immigrants by their undocumented status instead of criminality. Additionally, Mehan (1997) analyzed discourse concerning California's Proposition 187, a state bill passed in 1994 which denied public benefits for undocumented immigrants, and found a link between the embedding of the term illegal immigrant or illegal alien in arguments that were for the passing of Proposition 187 and the use of undocumented immigrant or undocumented worker in arguments against it. As Pearson (2010) notes, the threat narrative associated with illegal immigrant prompts more prejudice than the competition narrative of the undocumented worker, explaining, in part, why the arguments used by proponents of Proposition 187 held greater persuasive power.

While the former studies show that manipulation of immigration terms can exacerbate the perceived threat of immigrants, other studies show that the terms themselves hold little influence over individual perceptions. Ommundsen, Van Der Veer, Larsen, and Eilertsen (2014), Caicedo (2016), and Merolla, Ramakrishnan, and Haynes (2013) obtained data that appear to contradict Mehan's (1997) and Pearson's (2010) findings. Ommendsun, et al. (2014), Caicedo (2016), and Merolla, et al. (2013), each distributed questionnaires to various populations that analyzed if the participants would show greater prejudice towards immigrants framed as illegal aliens, illegal immigrants, undocumented immigrants, or unauthorized immigrants. As a whole, their findings showed that the terms used in the questionnaire did little to influence the opinions of the participants, although Ommundsen, et al. (2014) inexplicably found their participants actually perceived illegal aliens best when compared to undocumented immigrants or illegal immigrants. One possible reason for this discrepancy could be that the three studies that found minimal differences between the terms are the most recent studies. Perhaps the terminology codes have been metacognitively realized on both sides due to the bombardment of immigrant issues, like the DREAM Act and President Trump's rhetoric, giving both sides the understanding that regardless of how they are presented, illegal immigrants are undocumented immigrants, and whatever set of beliefs they have for their preferred term transfer to the other. Even though the specific terms did not elicit prejudice, Caicedo (2016) found that the participants' social communities had a significant impact on their level of prejudice, and Merolla, et al. (2013) found that the way in which the situation was framed in the question had a much greater impact than the terms used.

While the impact of the terms illegal alien, illegal immigrant, and undocumented immigrant, may have less on an impact on public opinion than some may perceive, the framing the media presents when it discusses immigrant issues impacts society's perception of immigrants at a much deeper level. Mehan (1997) found that in addition to consistent terminology used on both sides, the discourse strategies used for their arguments also differed greatly. In the arguments for Proposition 187, most discussed illegal immigrants in terms of the "enemy," "us vs them," and encouraged the public to look after their own "personal self-interest" (Mehan, 1997, p. 261), which greatly contrasted the appeals to the greater good and basic human rights by the opposition. Stewart, Pitts, and Osborne (2011) illustrated how media framing (i.e., labeling) can rally entire communities against another by using one undocumented immigrant who killed two teenage girls while driving drunk as a metonym for the entire Latino community in their town and a demonstration 
of the failure of the immigration system. This issue, in part, is exacerbated by the desire of the media to "give the masses what they want" (Miller, 1994 p. 21) by writing what they believe their target audience wishes to hear, regardless of contradictory facts and evidence. Dunn, Moore, and Nosek (2005) highlight the ease with which the media can shape public opinion by simply exchanging three buzzwords associated with terrorism (i.e., attackers, explosion, and plot) with words associated with the military (i.e., forces, bombing, and strategy) in an article. Even though the two articles were exactly the same, save for three words, the participants viewed the article with the military words to represent patriotism and our side, and the article with attackers, explosion, and plot as terrorism and referring to them/the enemy. In terms of immigration, the LA Times used many dehumanizing metaphors to describe immigrants, the most prevalent of which was as an animal in Santa Anna's (1999) study, which appeared to justify the harsh violation of human rights that immigrants experienced under that legislation.

As disturbing as the media's manipulation of public opinion is, equally unsettling is the research shows how court legislation and legal terminology follow the same pattern of justification through metaphors and framing. Cunningham-Parmeter (2011) analyzes discourse within immigration law to find that the common metaphor of immigrants as aliens, a flood, and an invasion, frequently frame immigrants as less than human due to their citizenship status. The researcher suggests that these words should be replaced with metaphors of migration and economic sanctuary in order to encourage reform rather than punishment. Johnson (1996) goes one step further and claims the term alien provides justification for sub-human treatment, such as Justice Antonin Scalia's call for arresting and deporting the "Alien juveniles" instead of releasing them to responsible adults versus Justice John Paul Stevens' commentary of the deplorable conditions of the "harmless children" in detention centers (pp. 279-280). If the language of the law confirms that undocumented immigrants, especially non-White immigrants, are not deserving of basic human rights, American society will continue to justify the prejudice and inhumane treatment rained upon undocumented immigrants.

Current research demonstrates that language largely fuels the discrimination of and racism shown toward undocumented immigrants through terminology, situation framing, metaphors, and other discourse strategies, particularly through the media and legal system. Despite the data that claim that terminology does not influence the general public, this study investigates if certain terminology is consistently framed in a way that presumes immigrants as being threatening or criminals when the terms illegal alien or illegal immigrant are used when compared with a more humanizing framework of undocumented immigrant. This hypothesis would explain the discrepancy between the lack of reaction to individual terms out of context when compared with the public's reaction to the discourse as a whole. This study extends the research of these scholars by analyzing the frequency, usage over time, presence in different media, and contexts of the aforementioned terms.

\section{Method}

This study used the Corpus of Contemporary American English (COCA, 2016) in order to analyze the frequency and contexts with which the media used the previously mentioned terms since 1990. A mixed-methods study was used to quantitatively identify the term frequencies from media usage and qualitatively analyze the presumption of criminality within randomly selected contexts.

For the quantitative aspect of this analysis, COCA was used to analyze the total documented uses of the terms in the media, the mediums the terms were used in, the usage of the terms over time, as well as the usage of the terms by specific media outlets. Qualitatively, 20 contexts of each of the terms (60 total) were selected from COCA using random sampling. A random number generator was used to select different contexts for the terms in order to preserve an unbiased review. Each term was then coded by the researchers based on the presumption of criminality in the contexts. For example, one context read, "Brutal murder in Dallas allegedly committed by a criminal illegal alien who was twice deported..." (COCA, 2016), and was coded criminal by the research, as not only was the immigrant specifically called a "criminal illegal alien," but it presents no presumption of innocence and a full assumption of criminality. A different context discussed a high school valedictorian who lost his scholarships because of his undocumented status. This context was coded non-criminal as it in no way implicated him with any deliberate criminal activity.

\section{Results}

Each of the research questions is addressed specifically in the following four sections. The first three questions address the quantitative results, and the fourth question analyzes the qualitative element of this study.

\subsection{Overall Term Frequency}

As shown in Figure 1, illegal immigrant was the most frequently used term with 367 tokens (i.e., occurrences) in COCA. Illegal alien had 257 tokens and undocumented immigrant had the least at 73 tokens. In terms of medium of usage, illegal immigrant and undocumented immigrant are fairly balanced between spoken use and usage in newspaper with 
illegal immigrant used in spoken situations $43 \%$ of the time and in newspapers $44 \%$ of the time, and undocumented immigrant used $47 \%$ in spoken usage and $33 \%$ in newspapers. Illegal alien, on the other hand, was used $62 \%$ of the time in spoken contexts and only in newspapers $11 \%$ of the time, showing a clear preference for its usage in spoken environments.

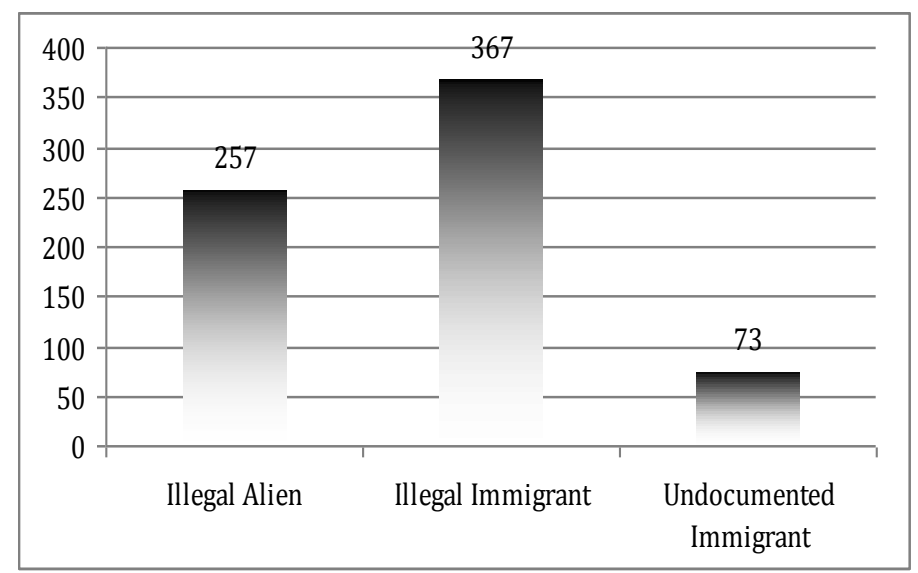

Figure 1. Total tokens of illegal immigrant terms in COCA

\subsection{Usage Over Time}

All three terms have exhibited an upward trend over time with particular increases in 2006, 2010, and 2015, as shown in Figure 2. Unlike illegal alien and illegal immigrant, the term undocumented immigrant did not begin use until 1994 and was not used more than three times a year until 2006, and was not used consistently until 2010.

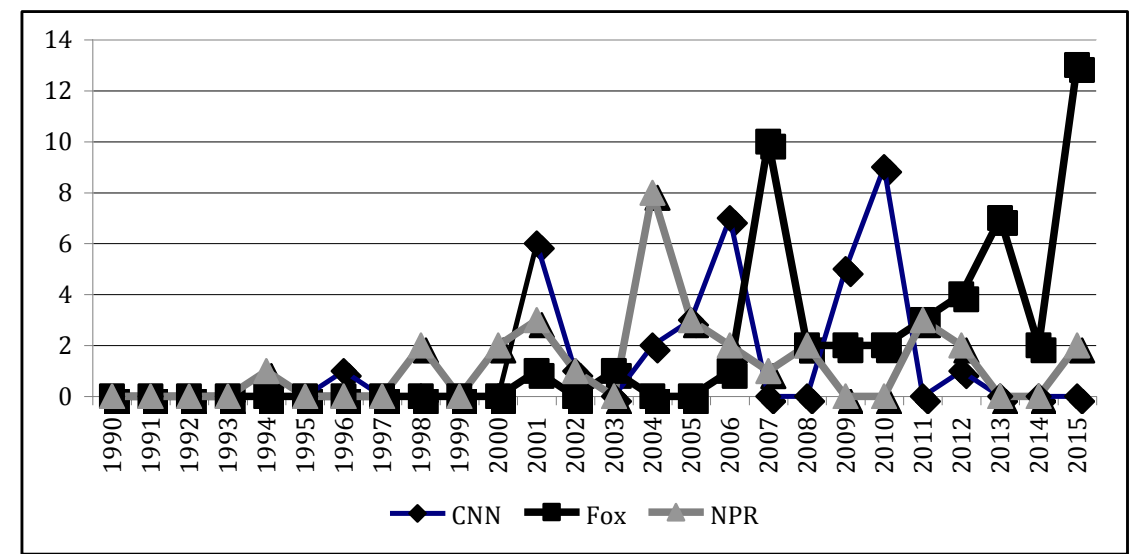

Figure 2. Use of Illegal Immigrant by Fox, CNN, and NPR from 1990-2015

\subsection{Media Term Preference}

The top three users of illegal alien in the media from 1990-2015 are CNN, Fox, and USA Today; they were also used frequently in academic contexts and fiction. However, CNN used 67\% of their tokens in 2005 and 2006 , and ceased usage of illegal alien all together in 2010, whereas Fox began using the term in 2003 and USA Today began using the term in 2009.

Fox, CNN, and NPR were the media outlets that used illegal immigrant the most. Usage of this label in various media outlets, however, was much more evenly distributed. While Fox has used illegal immigrant on a regular basis since 2006 to present, both CNN and NPR largely stopped their usage of it by 2010 . Specifically, NPR accounted for $24 \%$ of the total tokens for undocumented immigrant, using this term over three times as much as Academic sources; no other media source used undocumented immigrant more than five times in the 22-year span 1994-2015. NPR was also the only source to consistently use the term over time as did CNN, the media outlet with the third greatest usage, which only began using the term in 2015.

National Public Radio accounted for $24 \%$ of the total tokens for undocumented immigrant, using this term over three times as much did Academic sources; no other source used undocumented immigrant more than five times in the 22 
year span 1994-2015. NPR was also the only source to consistently use the term over time, as did CNN, the media outlet with the third greatest usage of the term, which only began it in 2015 .

\subsection{Contextual Analysis}

Based on a total sample of 60 contexts retrieved from COCA, undocumented immigrant presumed criminality the least with only $30 \%$ of tokens implying criminality (6 out of 20). Illegal immigrant had similar data with only $40 \%$ (8 out of 20) of the tokens presuming criminal intent, not a statistically significant difference from undocumented immigrant given the number of tokens taken. However, illegal alien presumed criminality $75 \%$ (15 out of 20) of the time, more than the criminal contexts from illegal immigrant and undocumented immigrant combined (Figure 3).

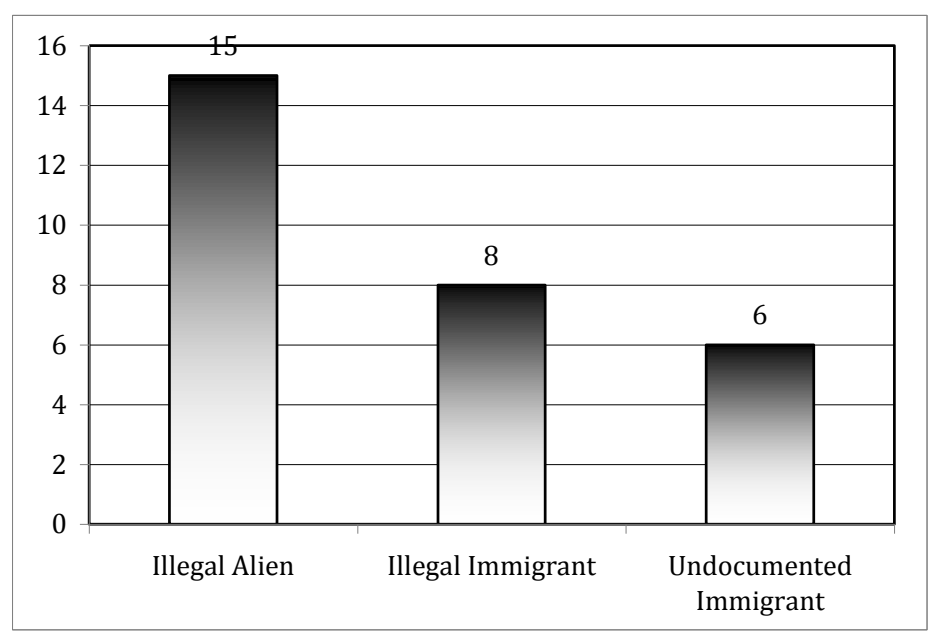

Figure 3. Number of contexts assuming criminality by term

\section{Discussion}

Based on the data gathered from COCA, it is clear to the authors that illegal immigrant is a term of choice in the media as a whole, but what does that say about the intent of the media? The following sections will discuss implications that can be made from each set of data analyzed.

\subsection{Frequency of Terms}

While the terms illegal immigrant and illegal alien have significantly more tokens than undocumented immigrant, this trend could largely be due to the newness of the term undocumented immigrant. Undocumented immigrant has been used more frequently in recent years and even gained parity with the other two terms in 2014, though the large increase in illegal alien and illegal immigrant in 2015 shows undocumented immigrant will not become the term of choice in the media any time soon.

Unlike the balanced use of illegal immigrant and undocumented immigrant in spoken contexts and newspapers, the use of illegal alien in predominantly spoken contexts yields interesting implications. Why is there a discrepancy? Illegal alien appears to be a term that is easier said than written, which means it is likely a term used as more of an emotional response rather than the thought out choice more associated with writing. Perhaps people recognize the dehumanizing implications of illegal alien when they take the time to write, but less so when they speak spontaneously.

\subsection{Usage Over Time}

Illegal alien separates from the commonalities the other terms exhibits in its usage over time as well. Illegal alien and illegal immigrant shared near equal usage in the 1990s and early 2000s, but began to diverge in the late 2000s with illegal alien taking a sharp decline in 2007. This discrepancy is likely caused by the same reason as the discrepancy in speaking and written contexts in illegal alien as well; people likely recognize the dehumanization the word alien implies. It had zero tokens used in 2013, appearing to phase out of use until its usage spiked in 2015.

Noteworthy spikes in all three terms occurred in 2006, 2010, and 2015, all of which correlate to heated debates about immigrants and immigration. In 2006, the Comprehensive Immigration Reform Act was proposed, but never passed. In 2010, Justice Sotomayor was sworn in as the first Hispanic Supreme Court justice of the United States, renewing talks of immigrants in the media. Since 2015, when Donald Trump first announced his presidency and his adamant stance against undocumented immigrants, the term illegal alien has reemerged in American media. 


\subsection{Presumption of Criminality}

The term Illegal alien's inherent presumption of criminality in the contexts analyzed explains why the term began to phase out over time and why people seem to be hesitant to write it down rather than speak it out loud. Actually, illegal immigrant and undocumented immigrant do not significantly differ in context. This similarity aligns with the research of Ommundsen, et al. (2014), Caicedo (2016), and Merolla, et al. (2013) in that immigrant terms prefaced with illegal do not appear to significantly affect the contexts they are used in when compared with terms using undocumented.

The fact that illegal immigrant and undocumented immigrant share similar contexts indicates that the term alien is more of an indicator of criminality than the term illegal, despite the association of illegal with criminality in all other contexts. This difference is likely due to the dehumanizing aspect of alien when compared with the extra-legal context of illegal. Immigrant indicates a person from another country, whereas alien implies the person is not even human and is therefore less deserving of human rights and sympathy.

\subsection{Media Preference}

While the terms illegal immigrant and undocumented immigrant appear in similar contexts, media outlets tend to show clear preference for the terms based on the frequency of their usage. As mentioned before, Fox dominates the current usage of illegal alien and illegal immigrant by a wide margin. In fact, since 2007, Fox alone accounts for $37.5 \%$ of the total usage of illegal alien and $22.4 \%$ of the total usage of illegal immigrant. NPR, on the other hand, accounts for $24 \%$ of the total usage of undocumented immigrant. While CNN was a heavy user of both illegal alien and illegal immigrant in the past, both media networks have recently made a shift to using undocumented immigrant instead. What drives the word choice for these media outlets?

According to a 2014 Pew Report (Political Polarization \& Media Habits), concerning political polarization in the media, Fox News is by far the news outlet of choice for people who identify as conservative, with $47 \%$ of consistently conservative and $31 \%$ of mostly conservative participants listing Fox as their primary source of political news. Conversely, CNN and NPR are the outlets of choice for the consistently liberal and mostly liberal participants in the study, with CNN viewed as the top choice for $15 \%$ of the consistently liberal and $20 \%$ of the mostly liberal, with NPR being preferred by $13 \%$ of the consistently liberal and $9 \%$ of the mostly liberal. CNN is also preferred by $20 \%$ of the mixed liberal/conservative participants, compared with $8 \%$ of that demographic preferring Fox News. Further, Fox News is by far the most trusted political news source for conservatives, with $72 \%$ of mostly conservative and $88 \%$ of consistently conservative participants saying they trust Fox News. Following the early trend, NPR is the most trusted source for the consistently liberal $(72 \%)$ and $\mathrm{CNN}$ is the most trusted source for the mostly liberal (66\%) and mixed liberal/conservative $(61 \%)$ participants.

Based on the clear partisanship shown by these three news outlets, the researchers argue that media outlets' choice of immigration terminology is used as a marker to denote partisanship to their viewers. Fox News, being the outlet of choice for conservatives, uses illegal immigrant and illegal alien to align itself with the Republican Party's stalwart stance on immigration. NPR and CNN, the most preferred and trusted sources of liberal viewers, use undocumented immigrant to reflect their partisan stance, aligned with the Democratic Party's more lenient immigration policies. While CNN formerly used illegal immigrant and illegal alien, the researchers purport that the network stopped the use of those terms and replaced them with undocumented immigrant to appeal to their liberal and mixed viewership base.

\section{Limitations and Conclusions}

One of the limitations of this study is that only a limited sample of contexts was selected. This could affect the way the terms illegal immigrant and illegal alien were viewed over time, as the contexts as a whole could potentially be less negative when further analyzed. Some tokens also could have been in the same text, which could potentially skew the data. As this study used COCA, the results only date back to 1990, which provides more of a limited scope of the evolution of these terms over time.

Based on the evidence presented in this study, it appears that while the terms illegal alien and undocumented immigrant align both semantically and pragmatically in their usage, illegal immigrant presumes criminality only $40 \%$ of the time, pragmatically assuming non-criminal intent in context despite semantically indicating criminality. More importantly, the use of these terms to mark political affiliation demonstrates more than simply group membership. Associating terms framed with illegal with the Republican Party matches the conservative view of deporting immigrants without proper legal documents due to their being in the country illegally. The use of undocumented immigrant by media outlets associated with liberals and the Democratic Party aligns with the liberal view of supporting amnesty over deportation.

Even though this study focused primarily on the use of undocumented immigrant, illegal immigrant, and illegal alien in the media, the rhetoric produced by the media ultimately reflects societal views. The media largely presents what they believe their viewers wish to hear and reflects the perceived political climate of their viewership. The reemergence in 
2015 of illegal alien from its near death from disuse in 2013, and its continued regular usage at this 2018 writing, indicates a cultural shift to a less welcoming environment toward undocumented immigrants, particularly in presuming inherent criminality (Lalami, 2018).

It is suggested that more research studies be conducted analyzing the impact of the media on public perception. More specifically, research needs to investigate if the media holds a stronger influence over public opinion than public opinion holds over the media. Though public opinion and the media appear to be inextricably connected, as both rely on and inform the other, it is imperative that the public have access to factual, unbiased information with which to develop research-grounded stances instead of simply parroting the rhetoric of partisan reporters. In terms of the immigration debate, do people feel disdain for undocumented immigrants of their own accord, or do certain media outlets frame them as being criminal or illegal aliens? Are others sympathetic to the plight of undocumented immigrants because of their own personal beliefs, or because the media has made a solid case for providing a path to citizenship? Ultimately, whether immigrants are described as being illegal or undocumented, their most important commonality with citizens of the United States must not be forgotten: they are human; they deserve to be recognized as such.

\section{References}

Caicedo, D. A. (2016). Alien, illegal, and undocumented: labeling, context, and worldview in the immigration debate and in the lives of undocumented youth. New York, NY: CUNY Academic Works.

Corpus of Contemporary American English. (2016). [COCA is a corpus of English] Retrieved from https://corpus.byu.edu/coca/

Cunningham-Parmeter, K. (2011). Alien language: Immigration metaphors and the jurisprudence of otherness. Fordham Law Review, 79, 1545-1598.

Dunn, E. W., Moore, M., \& Nosek, B. A. (2005). The war of the words: How linguistic differences in reporting shape perceptions of terrorism. Analyses of Social Issues and Public Policy, 5(1), 67-86. https://doi.org/10.1111/j.1530-2415.2005.00056.x

Gabbacia, D. R. (2010). Nations of immigrants: Do words matter? The Pluralist, 5(3), 5-31. https://doi.org/10.5406/pluralist.5.3.0005

Gamson, A., \& Wolfsfeld, G. (1993). Movements and media as interacting systems. Annals of the American Academy of Political and Social Science, 528, 114-125. https://doi.org/10.1177/0002716293528001009

Johnson, K. R. (1996). "Aliens" and the U.S. immigration laws: The social and legal construction of nonpersons. The University of Miami Inter-American Law Review, 28, 263-292.

Lalami, L. (2018, April). How ICE puts a generation at risk. The Nation. Retrieved from https://www.thenation.com/article/how-ice-puts-a-generation-at-risk/

Mehan, H. (1997). The discourse of the illegal immigration debate: A case study in the politics of representation. Discourse and Society, 8, 249-270. https://doi.org/10.1177/0957926597008002006

Merolla, J, S., Ramakrishnan, K., \& Haynes, C. (2013). "Illegal," "Undocumented," or "Unauthorized": Equivalency frames, issue frames, and public opinion on immigration. American Political Science Association, 11, 789-807. https://doi.org/10.1017/S1537592713002077

Miller, J. J. (1994). Immigration, the press and the new racism. Media Studies Journal, 8(2), 19-28.

Ommundsen, R., Van Der Veer, K., Larsen, K.S., \& Dag-Erik Eilertsen. (2014). Framing of unauthorized immigrants: The effects of labels on evaluations. Psychological Reports: Sociocultural Issues in Psychology, 114, 461-478. https://doi.org/10.2466/17.PR0.114k20w0

Paspalanova, M. (2008). Undocumented vs. illegal migrant: Towards terminological coherence. Migraciones Internacionales, 4(3), 79-90.

Pearson, M. R. (2010). How "undocumented workers" and "illegal aliens" affect prejudice toward Mexican immigrants. Social Influence, 5(2), 118-132. https://doi.org/10.1080/15534511003593679

Political Polarization \& Media Habits. (2014). Pew Research Center. Washington, D.C. Retrieved from http://www.journalism.org/2014/10/21/section-1-media-sources-distinct-favorites-emerge-on-the-left-and-right/

Santa Ana, O. (1999). 'Like an animal I was treated': anti-immigrant metaphor in US public discourse. Discourse and Society, 10, 191-224. https://doi.org/10.1177/0957926599010002004

Stewart, C. O., Pitts, M. J., \& Osborne, H. (2011). Mediated intergroup conflict: The discursive construction of "illegal immigrants" in a regional U.S. newspaper. Journal of Language and Social Psychology, 30(1), 8-27. 
https://doi.org/10.1177/0261927X10387099

U.S. Citizenship and Immigration Services (2018). Retrieved from https://www.uscis.gov/

\section{Copyrights}

Copyright for this article is retained by the author(s), with first publication rights granted to the journal.

This is an open-access article distributed under the terms and conditions of the Creative Commons Attribution license which permits unrestricted use, distribution, and reproduction in any medium, provided the original work is properly cited. 